\title{
DOENÇA NEURODEGENERATIVA RARAF CARACTERIZAÇÃo dOS PORTADORES DE DOENÇA DE HUNTINGTON E ATAXIA ESPINOCEREBELAR NA AMAZÔNIA OCIDENTAL, BRASIL
}

\author{
Rare neurodegenerative disease: characterization \\ of huntington disease patients and spinocerebelar \\ ataxia in western Amazon region, Brazil
}

Naime Oliveira Ramos ${ }^{1}$, Vivian Susi de Assis Canizares ${ }^{2}$, Andonai Krauze de França ${ }^{3}$, Thaynara Naiane Castro Campelo ${ }^{4}$, José Juliano Cedaro ${ }^{5}$

\footnotetext{
1. Bacharel em Enfermagem. Membro do Grupo de Pesquisa em Genética Humana da Fundação Universidade Federal de Rondônia. ORCID: https://orcid.org/0000-0003-0566-495X

2. Doutora em Biologia de Agentes Infecciosos e Parasitários. Docente do Departamento de Psicologia da Fundação Universidade Federal de Rondônia. ORCID: http://orcid.org/0000-0002-0504-9650

3. Doutor em Biologia Experimental, Docente da Fundação Universidade Federal de Rondônia e Coordenador do Grupo de Pesquisa em Genética Humana. ORCID: https://orcid.org/0000-0002-1612-0029

4. Acadêmica do curso de graduação em Enfermagem. Membro do grupo de Pesquisa em Genética Humana. ORCID: https://orcid.org/0000-0002-8185-4547

5. Doutor em Psicologia Escolar e do Desenvolvimento Humano. Docente do Departamento de Psicologia da Fundação Universidade Federal de Rondônia. ORCID: https://orcid.org/0000-0001-7479-6556
}

CONTATO: Naime Oliveira Ramos | Avenida Amazonas | Bairro Tiradentes n 6030 | Condomínio Villas de Belo Horizonte | casa 121 | CEP $76824-536$ | E-mail: andreiamaneira@hotmail.com

COMO CITAR: Ramos NO, Canizares VSA, França AK, Campelo TNC, Cedaro J. Doença neurodegenerativa rara caracterização dos portadores de Doença de Huntington e ataxia espinocerebelar na Amazônia Ocidental, Brasil. R. Saúde Públ. 2018 Dez;1(2):63-74 
RESUMO Objetivou-se neste estudo caracterizar portadores de doenças neurodegenerativas raras e familiares quanto aos aspectos sociais, clínicos e assistências, pois a cronicidade dessas patologias faz com que seus portadores vivam longos períodos de dependência, sendo incapazes de realizar atividades do cotidiano, necessitando de cuidadores integralmente. Trata-se de uma pesquisa qualitativa, descritiva, realizada por meio de dados coletados nos relatórios desenvolvidos pelo laboratório de pesquisa. A amostra foi composta por dois grupos, um com membros afetados por Doença de Huntington e outro com afetados por Ataxia Espinocerebelar 2. Observou-se que esses distúrbios trazem grande impacto para a vida desses indivíduos, interferindo nas atividades corriqueiras. Além disso, verificou-se falta de capacitações dos profissionais de saúde para o devido acolhimento dessas pessoas e, por isso, salienta-se a necessidade de implantação de políticas públicas visando o acompanhamento e proteção dos pacientes e familiares afetados por essas doenças.

PALAVRAS-CHAVE: Doenças Neurodegenerativas. Ataxias Espinocerebelares. Enfermagem em Saúde Comunitária. Avaliação em Saúde.

ABSTRACT The objective of this study was to characterize patients with rare neurodegenerative diseases and their families, regarding social, clinical and assistance aspects, because these pathologies chronicity leads their patients to experience long periods of dependence, being unable to perform daily activities, requiring full-time caregivers. This is a qualitative research with a descriptive approach, carried out through data collected from the reports developed by members of the research group. The sample consisted of two groups, one affected by Huntington Disease, and the other affected by Spinocerebellar Ataxia 2. It was noted that these disorders have a great impact on the life of the individuals, interfering in their daily life activities. In addition, there is a lack of trained professionals to embrace these people; thus, the need to implement public policies to follow and protect the patients and their families affected by this disease is highlighted.

KEYWORDS: Neurodegenerative Diseases. Spinocerebellar Ataxias. Community Health Nursing. Health Assessment.

\section{INTRODUÇÃO}

$\mathbf{A}$

$S$ doenças neurodegenerativas raras

(DNR) se caracterizam pela degeneração e/ou morte dos neurônios, ocasionando a perda progressiva e gradual das funções motoras, fisiológicas e cognitivas. Podem ser classificadas em genéticas e não genéticas'.

Neste estudo, as DNR enfocadas são as de etiologia genética. Dentre as mais conhecidas estão a Doença de Huntington (HD), a Doença de Alzheimer (DA), Esclerose Lateral Amiotrófica (ELA) e as Ataxias Espinocerebelares (SCA). As pesquisas realizadas nessa temática são limitadas e ainda não são conhecidas as causas das mutações ocorridas no DNA. Estudos apontam que as consequências dessas doenças genéticas podem estar associadas à variação do número de cópias ou a expressão alterada de alguns genes ${ }^{2,1}$.

A HD afeta o sistema nervoso central, sendo determinada pela presença dos movimentos coreicos, distúrbios comportamentais e demência. É uma doença dominante autossômica, causada pela repetição anormal (36 repetições ou mais) do 
trinucleotídeo Citosina-Adenina-Guanina (CAG), no cromossomo 4p16.3, no gene Huntingtina ${ }^{3}$.

As SCA são caracterizadas, tanto clínica quanto geneticamente, por sua heterogeneidade, evidenciada por mais de trinta tipos existentes. É uma desordem neurológica sendo responsável pela degeneração dos feixes espinocerebelares, piramidais e da coluna posterior, sendo que a maioria dos subtipos ocorre devido à expansão no trinucleotídeo CAG dos genes SCA 2, SCA 3, SCA 6 e SCA 10. A evidência do número aumentado do tripleto CAG, por meio de análise molecular, define o diagnóstico e o tipo de ataxia que acomete cada indivíduo?.

Devido à deterioração dos neurônios, a apresentação sintomatológica desses distúrbios ocorre de forma severa e muitas vezes precoce, levando a pessoa a óbito. A cronicidade das DNR faz com que seus portadores vivam longos períodos de dependência, sendo incapazes de realizar simples atividades do cotidiano, necessitando de um cuidador integralmente ${ }^{4}$.

No Brasil, a magnitude dos casos das DNR ainda não está mensurada por não haver um sistema que notifique esses distúrbios, além da falta de diagnóstico precoce ou erro de diagnóstico. Esse fato traz grandes preocupações em relação aos casos, devido ao impacto gerado na vida dos afetados e de suas famílias. Tendo em vista sua relevância, as DNR já são consideradas um grave problema de saúde pública, abrangendo ações nos três níveis de atenção à saúde, seja no acolhimento às famílias, diagnóstico ou reabilitação ${ }^{5}$.

O apoio de uma equipe multiprofissional é fundamental para a realização da assistência às famílias acometidas pelas DNR, devendo ser acompanhadas durante todos os ciclos da vida e na inserção desta pessoa nos cuidados paliativos, que deve acontecer o mais precoce possível, com apoio fisioterápico, terapia ocupacional, assistência social e psicológica, visando, sobretudo, o retardamento da progressão dos sintomas².

As informações prestadas para as famílias e pacientes são de fundamental importância, visto que contribuem para melhora da ansiedade desses indivíduos. Neste contexto se destacam aquelas direcionadas ao itinerário terapêutico que essas pessoas percorrem durante a trajetória da doença $a^{4.5}$

A atenção básica deve estar preparada para acolher essas pessoas, sendo o profissional de enfermagem o líder, atuando principalmente como educador da equipe da estratégia da saúde da família, utilizando instrumentalização específica para a implementação do cuidado, como a Sistematização da Assistência de Enfermagem/SAE e a criação do vínculo profissional-usuário para a realização do acolhimento, de forma humanizada, no Sistema Único de Saúde - SUS ${ }^{5}$

Sendo assim, este estudo teve como objetivo caracterizar portadores de doenças neurodegenerativas raras e familiares quanto aos seus aspectos sociais, clínicos e assistenciais.

\section{METODOLOGIA}

Este trabalho insere-se em um programa mais amplo coordenado por pesquisadores vinculados ao grupo de pesquisa do Laboratório de Genética Humana (LGH), pertencente ao Departamento de Medicina da Universidade Federal de Rondônia (UNIR), que visa contribuir para o maior conhecimento sobre as DNR.

Trata-se de um estudo de modalidade qualitativa com abordagem descritiva, realizado por meio de dados coletados dos relatórios e instrumentos de pesquisa, assim como pela sistematização da assistência de enfermagem desenvolvida por membros do grupo de pesquisa durante as visitas domiciliares.

Durante o período de estudo foram acompanhadas sete famílias acometidas com algum tipo de DNR, residentes em municípios de Rondônia (Porto Velho, Guajará-Mirim, Cacoal, Buritis) e Amazonas (Apuí). A amostra foi delimitada a duas 
famílias, sendo uma portadora de HD e outra de SCA tipo 2. Optou-se por essa abordagem em virtude dessas famílias serem as que melhor representam o objeto de estudo e por apresentarem maior número de indivíduos acometidos.

A identificação e o contato inicial com os portadores e famílias foram realizados por algumas unidades de saúde do município de Porto Velho, sendo elas: Ambulatório de Doenças Genéticas Raras da Policlínica Oswaldo Cruz/POC e Centro de Atenção Psicossocial/CAPS Madeira Mamoré. Além dessas instituições, também houve contato direto dos pesquisadores aos portadores e suas famílias por meio de procura espontânea destes ao Laboratório de Genética da Universidade Federal de Rondônia.

Critério de inclusão para participação da pesquisa: todos os indivíduos com sintomas clínicos e/ou comprovação molecular de DNR e/ ou pertencentes à família com histórico de alguma DNR.

Foram realizadas entrevistas utilizando-se um formulário específico contendo informações como identificação socioeconômica, questões sobre hábitos de vida, condições de saúde e outros aspectos da dinâmica pessoal e familiar, observados e relatados durante as visitas domiciliares que aconteceram entre dezembro de 2016 a maio de 2017.

Realizaram-se ainda anamnese e exames físicos para a elaboração da SAE (Sistematização da Assistência em Enfermagem), que é um instrumento utilizado pelo enfermeiro para prestar assistência de forma individualizada e sistematizada, por meio dos registros das informações sobre o paciente, contribuindo para a qualidade do cuidado de enfermagem de maneira humanizada6.

A utilização de alguns instrumentos como o Genograma e Ecomapa possibilitaram o acompanhamento e entendimento da dinâmica familiar dos portadores de HD e SCA2.

O primeiro consiste em uma ferramenta para a visualização da estrutura familiar em três gerações, assim como sua composição, relações, fatores culturais, emocionais e sociais que envolvem os seus membros?. Já o segundo representa graficamente os recursos disponíveis e de acesso pela família. Nele, visualizam-se as redes e relações da família com a comunidade?

Para fins de tabulação das informações, foi construído um banco de dados no programa Microsoft Office Excel 2007, objetivando organizar, resumir e descrever os aspectos importantes dos dados coletados durante toda a pesquisa, como as variáveis sexo, idade, renda, nível de escolaridade concepção do indivíduo frente à doença (acometido ou não), entre outros.

Essa pesquisa insere-se no projeto "Screening Mutacional e Aspectos Clínicos de Pacientes com Suspeitas de Doenças Neurodegenerativas Raras e Seus Aspectos Psicossociais na Amazônia Ocidental", tendo sido encaminhada para a análise do Comitê de Ética em Pesquisa - CEP. recebendo parecer favorável, sob o número 1.849.777, em 02 de dezembro de 2016 (CAAE 59260516.0.0000.5300), com base na Resolução 466/2012 do Conselho Nacional de Saúde ${ }^{8}$.

\section{RESULTADOS E DISCUSSÃO CARACTERIZAÇÃO DAS FAMILIAS}

Cada família do estudo foi caracterizada conforme grupos domiciliares, ou seja, são indivíduos que se consideram da família e que residem na mesma casa, tendo aceitado, voluntariamente, participar desta pesquisa ${ }^{9}$.

Para uma melhor dinâmica da apresentação das informações da pesquisa foi denominada Família 1 para os membros afetados pela HD e Família 2 aqueles acometidos pela SCA2.

A Família 1 é composta por 39 pessoas, pertencentes a cinco gerações, sendo 21 do sexo 
feminino, com faixa etária entre um e 37 anos, e 18 do sexo masculino, cuja amplitude da faixa etária se estende entre sete e 59 anos.

O grupo domiciliar de enfoque é composto pelo patriarca, um enteado, três filhos biológicos. A essas cinco pessoas acrescenta-se outro filho biológico portador de HD, sua esposa e duas filhas desse casal. Por serem dependentes financeiramente do patriarca, foram enquadradas dentro do mesmo domicílio. De tal maneira pertencem a esse grupo nove pessoas, destacando que a matriarca foi a óbito em 2014, devido a complicações geradas pela HD.

O desenvolvimento do genograma deste grupo domiciliar (Figura 1) permite o entendimento sobre como cada indivíduo se insere nesta família.

O patriarca é trabalhador rural, possui 59 anos e possui a função de ser o principal cuidador dos indivíduos afetados. Possui nove filhos biológicos com a primeira esposa e mais dois no relacionamento atual. Além desses filhos, também cuida do enteado que tem 38 anos e possuí uma deficiência mental sem diagnóstico definido, não sendo portador de HD. Os filhos desse patriarca, acometidos por HD, a partir de então denominados pelas letras $A, B, C$ e D, terão maior enfoque na análise das questões propostas neste estudo.

O primeiro membro da família afetado é a filha A, que tem 37 anos, é portadora de HD confirmada por análise molecular. É divorciada, possui três filhos, sendo o primeiro do sexo feminino, fruto de um relacionamento na juventude, que por sua vez já é mãe e reside em outra cidade. Essa paciente que chamamos de A também é genitora de mais dois meninos, fruto de um relacionamento que findou após o aparecimento dos primeiros sintomas da HD. Esses filhos, com idade inferior a 18 anos, residem com o pai, pois ela não possui mais condições de cuidá-los. Apesar das condições avançadas da doença, incluindo dificuldades de comunicação, ela frequentemente demonstra sentir saudades dos filhos e o desejo de estar com eles.

Os sintomas em A acentuaram-se há quatro anos e atualmente apresenta alto grau de comprometimento neuropsicomotor. Recebe Benefício de Prestação Continuada (BPC) e tal recurso ajuda seu progenitor a manter os custos da casa onde vivem.

A filha B tem 35 anos e é divorciada. Possui cinco filhos, com os quais tem pouca relação. A sua filha mais velha tem 20 anos, é casada e tem um comportamento instável, ora residindo com o marido, ora morando com algum parente. Tem uma filha menor de dois anos, que deixou aos cuidados do pai da criança e dos pais dele. Os outros filhos de B são menores de idade e vivem com o pai em uma região rural de Porto Velho. B já apresenta grave comprometimento motor e manifestações psiquiátricas, que às vezes implica em agressões, sobretudo direcionado a sua irmã (filha A).

O filho C descobriu que é portador de HD no decorrer da pesquisa e apresenta um comprometimento mais leve quando comparado aos demais irmãos. Tem 33 anos e só recentemente passou a receber BPC. Há algum tempo não consegue emprego, pois a sintomatologia da doença acarreta lentidão de pensamentos e ações. É casado e vive com a esposa de 33 anos, com quem tem duas filhas (sete e dez anos), A esposa, por sua vez, tem um filho adolescente, oriundo de outro relacionamento.

O filho D é solteiro, tem 26 anos, portador de HD, com diagnóstico recente. Contudo, apresenta acentuado grau de comprometimento psicológico e psiquiátrico desde o final da adolescência, implicando inclusive em internações. Passa a maior parte do tempo deitado, debaixo de cobertas, apesar do calor escaldante da região amazônica e seu quarto não ter ventilador ou aparelho de ar condicionado.

A renda familiar é de três salários mínimos, incluindo renda como agricultor do patriarca e os dois auxílios de BPC, recebido pelos indivíduos $A$ e C. $O$ indivíduo B recebe Bolsa Família, porém o benefício fica com o pai das crianças. Os demais não possuem qualquer vínculo empregatício e 
Figura 1. Representação gráfica do genograma do grupo domiciliar da Família 1.

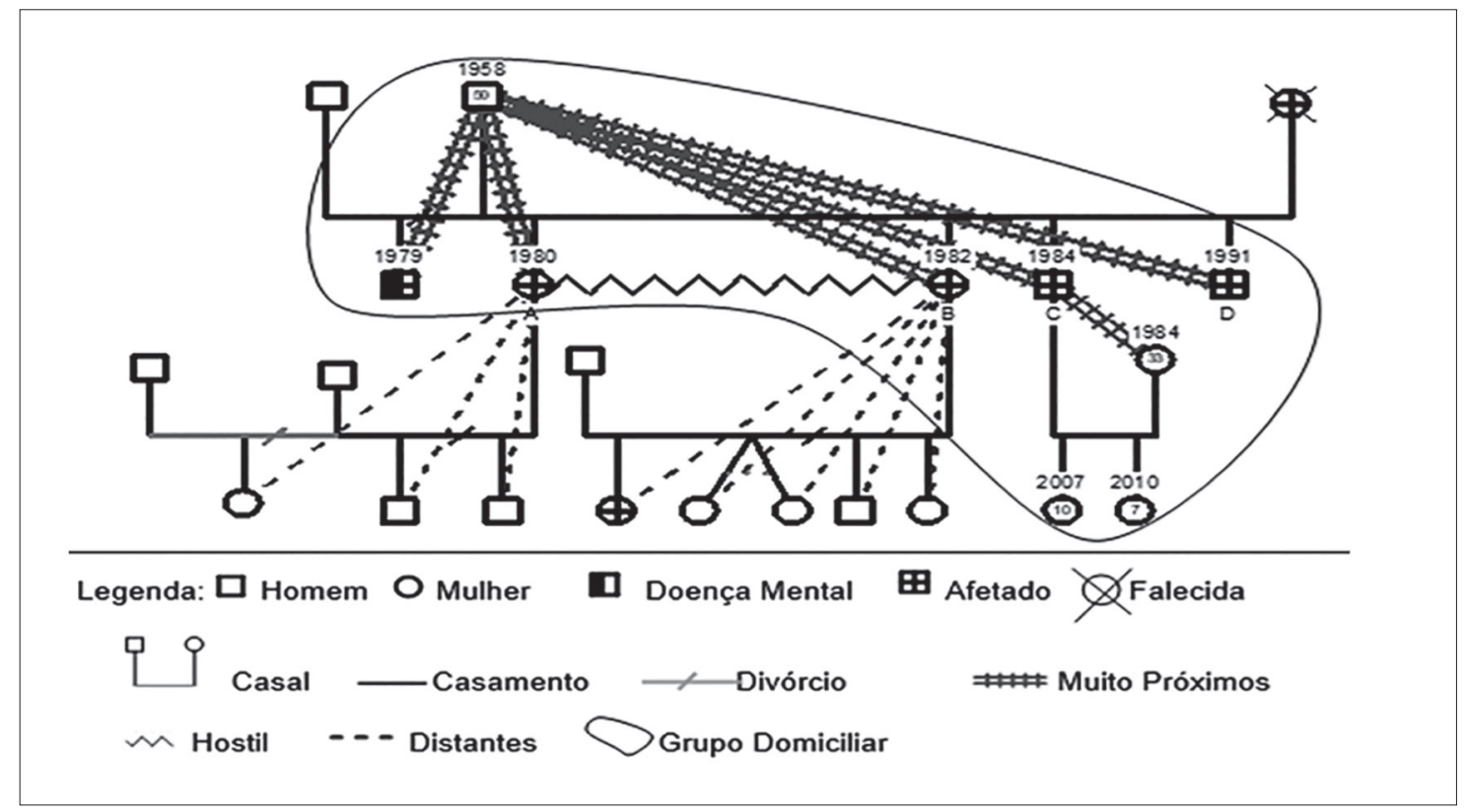

Laboratório de Genética Humana da Unir, 2017.

nem recebem algum tipo de auxílio, favorecendo o aumento da situação de vulnerabilidade desses indivíduos, pois carecem de alimentos especiais, muitos remédios e gastos com deslocamentos.

Em relação à escolaridade deste grupo, apenas um dos membros chegou a concluir o ensino médio (filho C). O filho B não completou o ensino médio, o filho $D$ e a esposa do filho C concluíram o ensino fundamental, enquanto o patriarca da família, seu enteado e a filha A não chegaram a concluir as séries escolares iniciais. As crianças, netas do patriarca, estão regularmente matriculadas em escolas da rede pública.

Diante disso, é possível perceber que a renda não é o único fator de situação de vulnerabilidade que esses individuos apresentam, mas também a baixa escolaridade, que interfere diretamente no entendimento das questões sociais que os cercam, assim como no entendimento da doença e de seus agravamentos. Isto posto, é importante destacar a necessidade de proteção desses indivíduos pelas políticas sociais, objetivando intervenções efetivas na assistência visando assegurar-lhes condições dignas de vida ${ }^{10}$.

Todos seguem vertentes evangélicas neopentecostais, porém devido às restrições impostas pela HD não participam das atividades religiosas nos templos.

Alguns membros deste grupo, como o filho C. sua esposa e filhas, conseguem realizar algumas atividades de lazer, como passeios e visitas à casa de outros parentes. Os demais têm suas atividades limitadas ao domicílio, que fica em uma área rural e só costumam sair de lá para consultas ou exames médicos, implicando em uma grande logística, devido à dificuldade de locomoção e por residirem em local de difícil acesso. Como forma de lazer participam apenas das atividades realizadas pelos membros do LGH em alguns momentos das visitas domiciliares, como jogos, pinturas e desenhos.

É possível verificar no ecomapa (Figura 2) que as relações com a comunidade são fracas e 
Figura 2. Representação gráfica do ecomapa do grupo domiciliar da Família 1.

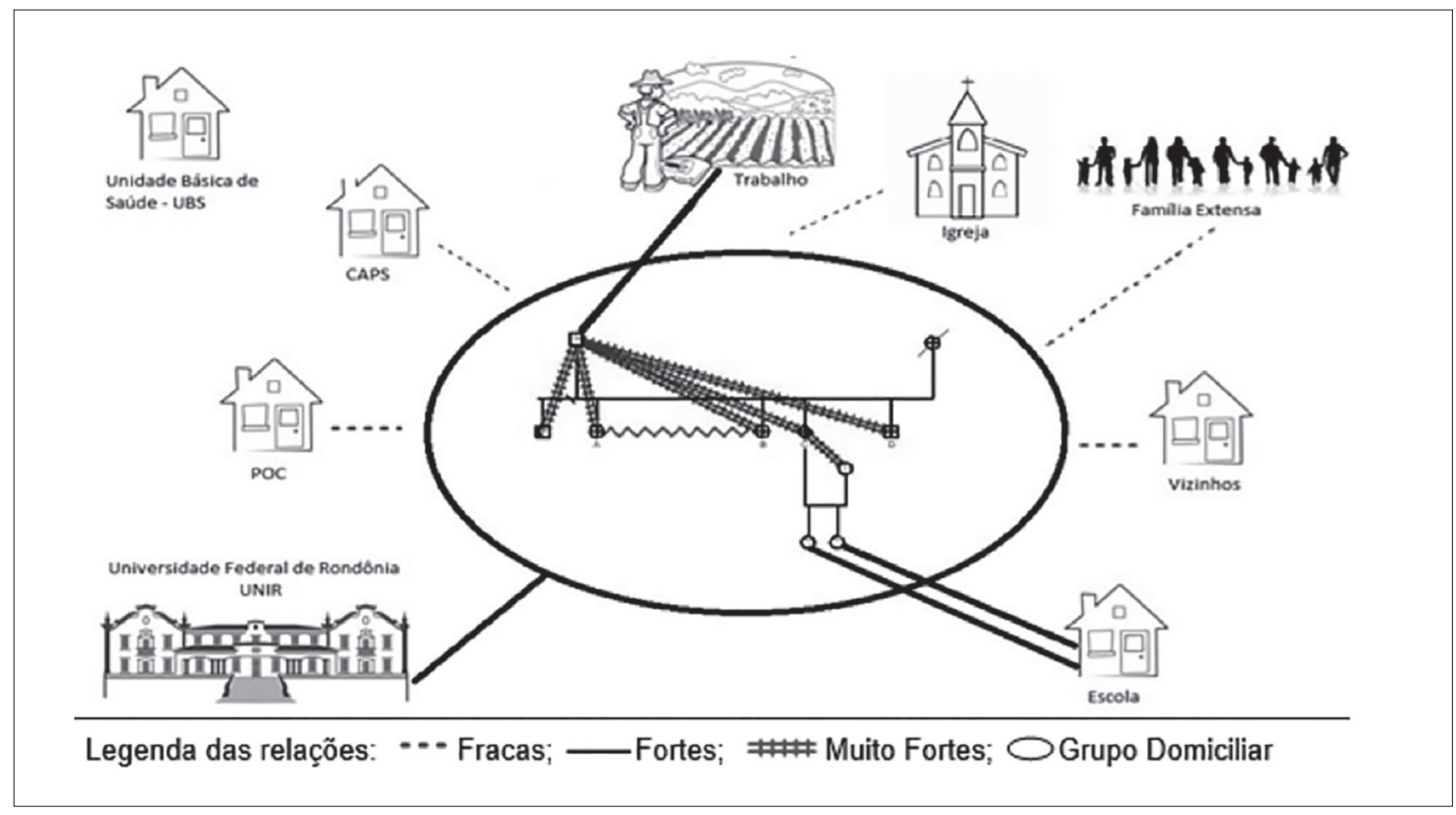

Laboratório de Genética Humana da Unir, 2017.

muitas vezes inexistentes, principalmente no que se refere aos serviços de saúde, dos quais essa família depende fundamentalmente, pois os pacientes possuem necessidade de assistência multidisciplinar ininterruptamente.

A casa em que residem atualmente é cedida pelo empregador do patriarca, a qual é construída em madeira, estando em péssimo estado de conservação: possui muitas frestas entre as tábuas, não possui forro e apresenta piso irregular. Há sete cômodos (sala, três quartos, dois banheiros, com apenas um deles em condições de uso e cozinha). Na parte externa há uma varanda. Como fica em área de região rural, é frequente o aparecimento de aranhas e cobras, principalmente no período de chuvas.

As precariedades na estrutura da moradia puderam ser observadas nas visitas semanais realizadas. Há várias condições que podem vir a comprometer à integridade dos moradores, devido aos constantes riscos que estão expostos, como risco de queda que está relacionado ao nivelamento do piso de entrada dos cômodos e presença de superfície irregular com uma extensa abertura no piso do banheiro. A falta de equilíbrio e de coordenação motora dos acometidos por HD torna a deambulação cada vez mais difícil nesses ambientes, necessitando de diversas adaptações.

Destaca-se ainda a potencialidade de risco ao suicídio ou de acidentes relacionados a objetos cortantes e herbicidas, expostos em locais indevidos e de fácil acesso, trazendo grandes preocupações, pois os portadores de HD tendem a apresentar distúrbios comportamentais de agressividade e depressão durante a progressão da doença ${ }^{3}$.

Em toda a estrutura da casa observa-se a presença de grande umidade. Os cômodos são pouco arejados e a incidência de luz solar é escassa, favorecendo a proliferação de insetos, roedores, fungos e até o aparecimento de animais peçonhentos, tornando-os vulneráveis a acidentes e a outras comorbidades.

A família do estudo acometida por SCA2, a qual denominaremos Família 2, é composta por 
55 pessoas, que estão distribuídas em quatro gerações, sendo 29 do sexo feminino e 26 do sexo masculino. Até o momento da pesquisa o número total de indivíduos afetados pela doença era de 15. sendo que sete foram a óbito.
O grupo domiciliar abordado é composto por quatro pessoas, sendo um casal, seu filho e a cunhada, cujos acometidos por SCA2 serão denominados pelas letras $\mathrm{E}$ e $\mathrm{F}$.

Figura 3. Representação gráfica do genograma do grupo domiciliar da família 2.

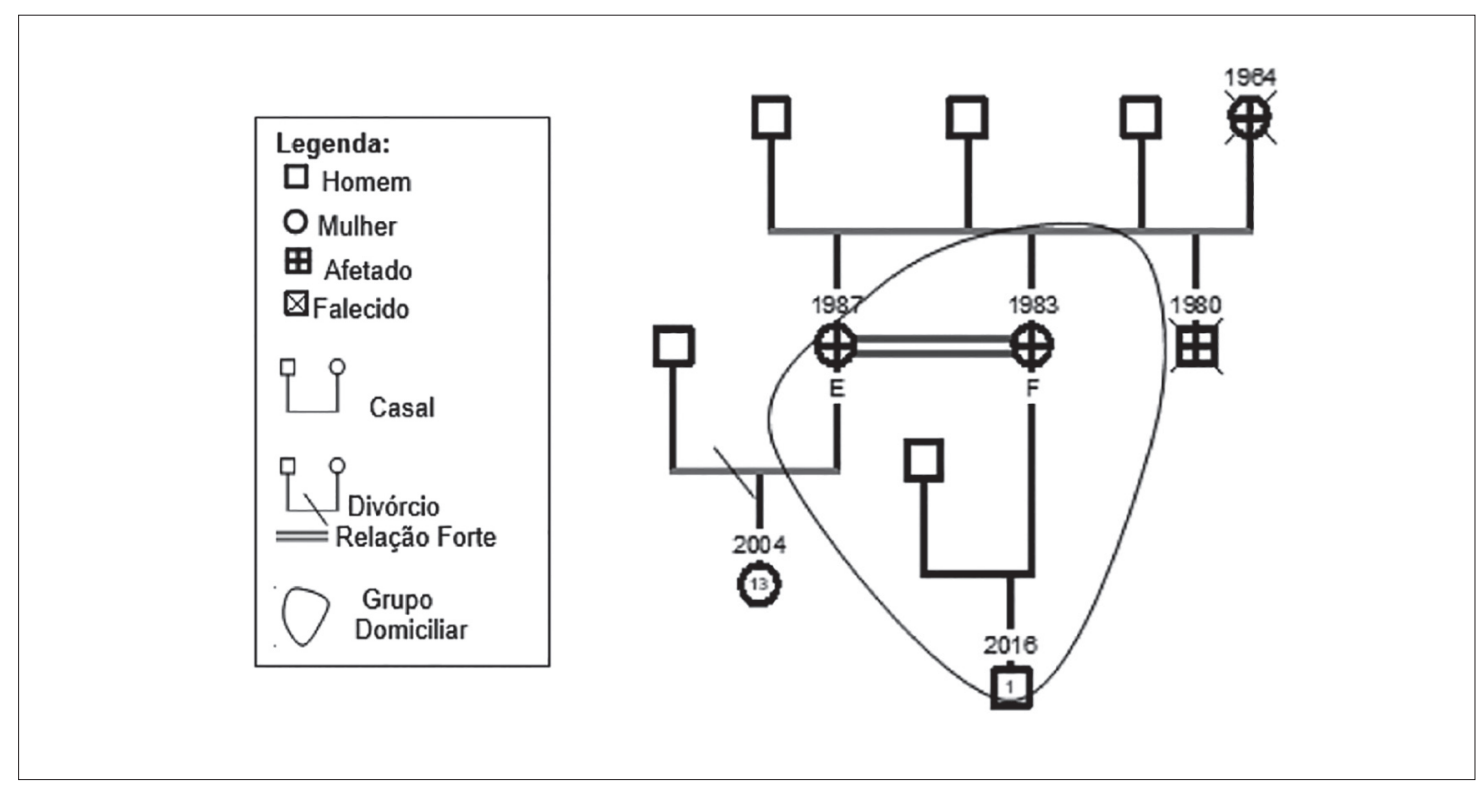

Laboratório de Genética Humana da Unir, 2017.

Durante a construção do genograma (Figura 3) deste grupo domiciliar foi possível observar a presença do gene mutante em 100\% dos filhos da matriarca. Além disso, constatou-se que após o agravamento dos sintomas de E, seu marido a abandonou, deixando-a aos cuidados da irmã mais velha (indivíduo F), também portadora de SCA2.

O indivíduo $E$ é do sexo feminino e tem 30 anos. É divorciada e está aposentada por invalidez. Tem uma filha de 13 anos, a qual está sob os cuidados e responsabilidade legal do avô, pois ela não tem condições de exercer tais funções. Registra-se que a manifestação dos sintomas de SCA2 teve início aos 14 anos e que sua mãe e seu irmão mais velho foram a óbito com sintomatologia da mesma doença. Atualmente vive com o pai e sua condição de saúde é preocupante, pois sofre de severo comprometimento físico e cognitivo, afetando sua mobilidade, obrigando-a locomoverse apenas em cadeira de rodas. Também apresenta dislalia e disartria acentuadas, com dificuldade na deglutição, apresentando episódios de engasgos constantes, com risco de broncoaspiração.

A irmã mais velha (individuo F) tem 34 anos, é casada e recebe benefício devido à deficiência, e tem um filho de um ano de idade. Os sintomas da doença iniciaram há nove anos. Considerando as condições da irmã mais nova (indivíduo E), seus sintomas são moderados, com vertigens, disfagia, disartria, dismetria, marcha atáxica, passos irregulares, lentos, deambulação somente com auxílio e incoordenação motora. 
Durante a gestação teve grandes complicações, desenvolvendo hipertensão e diabetes gestacional de difícil controle, apresentando pré-eclâmpsia grave. Devido às complicações e agravamento do seu quadro clínico, a gestação teve que ser interrompida com 37 semanas por meio de cesariana. Contudo, aparentemente, não houve sequelas para a criança, cujo desenvolvimento cognitivo e motor correspondente à idade esperada. Seu marido tem 33 anos e trabalha como autônomo. A renda familiar é inferior a três salários mínimos, incluindo duas aposentadorias. De tal modo, acaba sendo insuficiente para suprir todas as necessidades das pessoas que vivem na casa.

Em relação ao nível de escolaridade, o indivíduo $\mathrm{F}$ e seu marido cursaram o ensino médio. Sua irmã (E) concluiu o Ensino Fundamental. Embora sejam acometidas pela mesma doença, observa-se que a manifestação foi divergente nesses dois casos, sendo que o indivíduo E iniciou a manifestação dos primeiros sintomas ainda na adolescência, diferente do indivíduo F, que teve a manifestação da doença apenas na fase adulta, ou seja, possibilitou que ela cursasse todo o Ensino Médio sem dificuldades aparentes, além de ter uma vida social sem limitações.

Este grupo domiciliar é pertencente a uma vertente evangélica, porém não frequenta a igreja regularmente. Afirmam também que não costumam realizar outras atividades fora de casa, devido à dificuldade de locomoção. É possível observar no ecomapa (Figura 4) que as relações com a comunidade são fracas.

Destaca-se que houve, em algum momento, o apoio da Unidade Básica de Saúde/UBS que é referência do bairro onde moram, porém a assistência era limitada ao acompanhamento e consultas relacionadas à condição de gestante em que o indivíduo $\mathrm{F}$ se encontrava, não havendo um olhar amplo e envolvendo equipe multiprofissional, como previsto pela Portaria 199/2014 do Ministério da Saúde.

Figura 4. Representação gráfica do ecomapa do grupo domiciliar da Família 2.

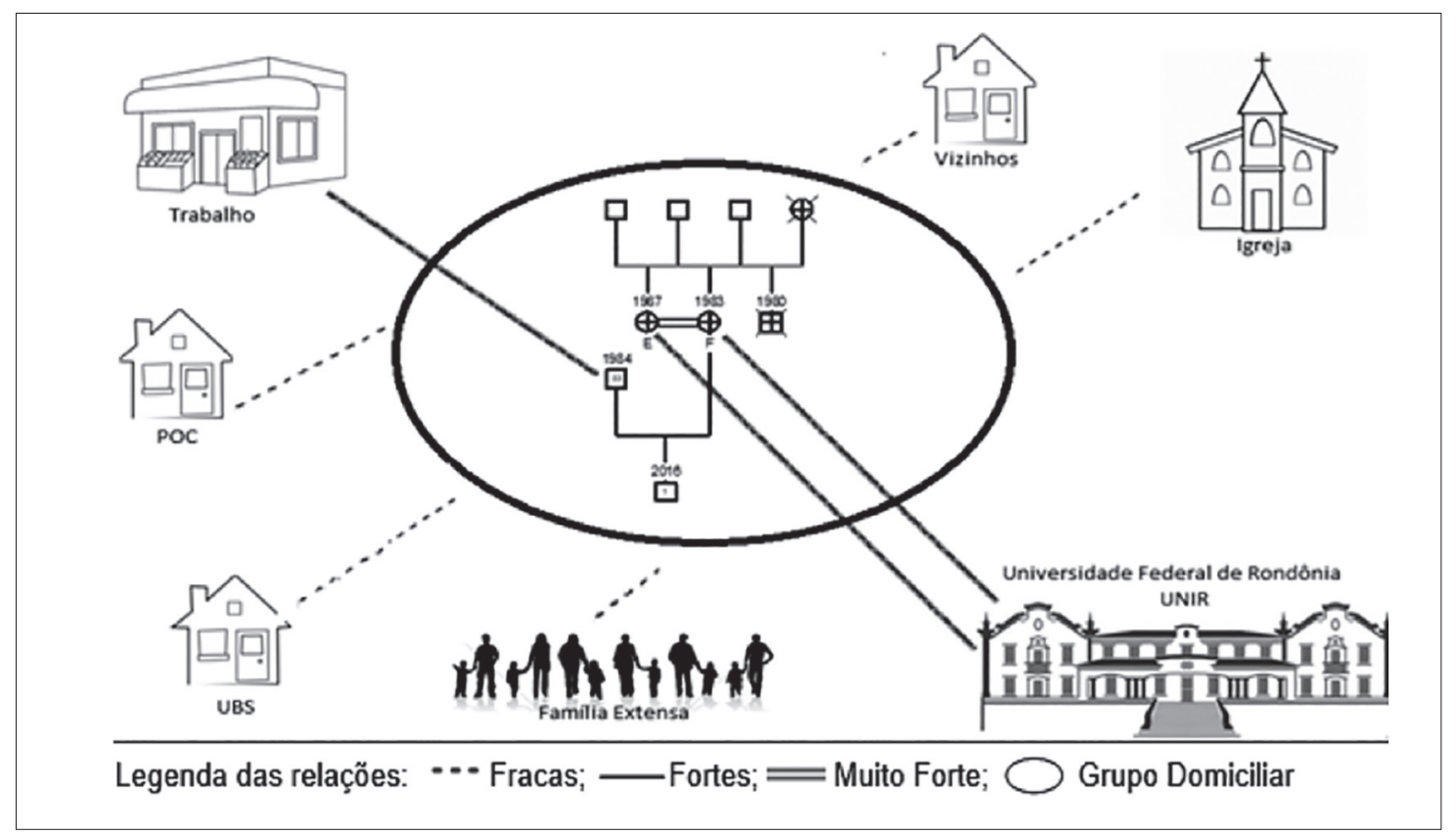

Laboratório de Genética Humana da Unir, 2017. 
A casa na qual residem é de propriedade da família, sendo uma construção de alvenaria, com cinco cômodos (sala, dois quartos, cozinha e banheiro), e não possui qualquer tipo de adaptação para a atual condição de saúde das duas irmãs causando possivel risco de queda e desconforto em relação às limitações impostas pela doença.

\section{SISTEMATIZAÇÃO DA ASSISTÊNCIA DE ENFERMAGEM (SAE)}

Segundo o Art. 11, da Lei $n^{\circ}$ 7.498, de 25 de junho de 1986, referente ao Exercício Profissional da Enfermagem, e a Resolução n 358/2009, do Conselho Federal de Enfermagem, a SAE é uma atividade privativa do enfermeiro, que consiste em realizar a identificação das situações de saúde e doença, subsidiando a prescrição e a implementação das ações de assistência de enfermagem, de forma a contribuir para promoção, prevenção, recuperação e reabilitação da saúde do indivíduo, da família e da comunidade ${ }^{11,12}$

Neste contexto, a implementação da SAE dos indivíduos desta pesquisa é de fundamental importância para a elaboração de um plano de cuidados individualizado, visando melhorar a

Quadro 1 Principais problemas encontrados, diagnósticos de enfermagem e intervenções dos portadores de HD e SCA2.

\begin{tabular}{|c|c|c|c|}
\hline & $\begin{array}{l}\text { PROBLEMAS } \\
\text { ENCONTRADOS }\end{array}$ & $\begin{array}{l}\text { DIAGNÓSTICOS DE } \\
\text { ENFERMAGEM }\end{array}$ & INTERVENÇÕES \\
\hline \multirow[t]{2}{*}{ A } & \multirow{2}{*}{$\begin{array}{l}\text { Desorientação; } \\
\text { Dificuldade de comunicação; } \\
\text { Higiene corporal insatisfatória; } \\
\text { Engasgos frequentes; } \\
\text { Incontinência intestinal; } \\
\text { Incontinência urinária; } \\
\text { Coreia; } \\
\text { Amplitude de movimentos } \\
\text { reduzidos; } \\
\text { Dificuldade de deambular. }\end{array}$} & $\begin{array}{l}\text { Deglutição prejudicada relacionada a } \\
\text { problemas neurológicos caracterizados } \\
\text { por engasgo antes de deglutir. }\end{array}$ & $\begin{array}{l}\text {-Orientar o cuidador quanto à observação } \\
\text { da deglutição e o esvaziamento da boca } \\
\text { durante as refeições; } \\
\text {-Orientar o cuidador quanto à preparação de } \\
\text { alimentos pastosos. }\end{array}$ \\
\hline & & $\begin{array}{l}\text { Incontinência intestinal relacionada à } \\
\text { diminuição geral no tônus muscular } \\
\text { caracterizado por incapacidade de } \\
\text { retardar a evacuação. }\end{array}$ & $\begin{array}{l}\text {-Orientar o cuidador sobre a manutenção } \\
\text { da higiene íntima e manter pele seca } \\
\text { continuamente; } \\
\text {-Orientar o cuidador quanto à troca das } \\
\text { roupas/fraldas sempre que sujas. }\end{array}$ \\
\hline \multirow[t]{2}{*}{ B } & \multirow[t]{2}{*}{$\begin{array}{l}\text { Higiene corporal insatisfatória; } \\
\text { Pediculose; } \\
\text { Algia na região epigástrica e } \\
\text { em membros inferiores; } \\
\text { Constipação; } \\
\text { Incontinência urinária. }\end{array}$} & $\begin{array}{l}\text { Incontinência urinária funcional } \\
\text { relacionada a prejuízo neuromuscular } \\
\text { caracterizado por perda de urina antes } \\
\text { de alcançar o banheiro. }\end{array}$ & $\begin{array}{l}\text {-Orientar sobre a manutenção da higiene } \\
\text { intima e manter pele seca continuamente; } \\
\text {-Estimular a realizar o exercício de Kegel. } \\
\text {-Orientar o cuidador quanto à redução de } \\
\text { alimentos irritantes vesicais (café, bebidas } \\
\text { ácidas, pimenta). }\end{array}$ \\
\hline & & $\begin{array}{l}\text { Constipação relacionada à motilidade } \\
\text { gastrintestinal diminuida caracterizada } \\
\text { por redução na frequência das fezes e } \\
\text { por ruídos intestinais hipoativos. }\end{array}$ & $\begin{array}{l}\text {-Orientar quanto à ingestão de alimentos } \\
\text { que contenham fibras como: legumes, } \\
\text { verduras, aveia. } \\
\text {-Orientar quanto à ingestão hídrica } \\
\text { fracionada, pelo menos } 2 \text { L, por dia. }\end{array}$ \\
\hline \multirow[t]{2}{*}{ C } & \multirow[t]{2}{*}{$\begin{array}{l}\text { Alteração de humor; } \\
\text { Dificuldade na marcha; }\end{array}$} & $\begin{array}{l}\text { Mobilidade física prejudicada } \\
\text { relacionada ao controle muscular } \\
\text { diminuido caracterizado por } \\
\text { movimentos descoordenados, tremor } \\
\text { induzido pelo movimento. }\end{array}$ & $\begin{array}{l}\text {-Encaminhar para Fisioterapeuta; } \\
\text {-Realizar exercícios passivos e ativos; } \\
\text {-Orientar quanto às caminhadas de pelo } \\
\text { menos } 30 \text { minutos, nas redondezas da casa. }\end{array}$ \\
\hline & & $\begin{array}{l}\text { Regulação do humor prejudicada } \\
\text { relacionado à doença crônica } \\
\text { caracterizada por agressividade, } \\
\text { ansiedade e agitação. }\end{array}$ & $\begin{array}{l}\text {-Diminuir os fatores estressores como } \\
\text { ruídos; } \\
\text {-Encaminhar para o Psiquiatra; } \\
\text {-Administrar medicações prescritas. }\end{array}$ \\
\hline
\end{tabular}




\begin{tabular}{|c|c|c|c|}
\hline & $\begin{array}{l}\text { PROBLEMAS } \\
\text { ENCONTRADOS }\end{array}$ & $\begin{array}{l}\text { DIAGNÓSTICOS DE } \\
\text { ENFERMAGEM }\end{array}$ & INTERVENÇÕES \\
\hline \multirow[t]{2}{*}{ D } & \multirow[t]{2}{*}{$\begin{array}{l}\text { Insônia; } \\
\text { Higiene insatisfatória, } \\
\text { Baixo peso; } \\
\text { Dor em membros inferiores. }\end{array}$} & $\begin{array}{l}\text { Déficit no autocuidado para banho } \\
\text { relacionado ao prejuízo neuromuscular } \\
\text { caracterizado por odor fétido, presença } \\
\text { moderada de sujidade em couro } \\
\text { cabeludo. }\end{array}$ & $\begin{array}{l}\text {-Estimular e explicar sobre a importância da } \\
\text { realização da higiene corporal; } \\
\text {-Orientar quanto ao uso de produtos de } \\
\text { higiene como shampoo, condicionador e } \\
\text { sabonete. }\end{array}$ \\
\hline & & $\begin{array}{l}\text { Insônia relacionada por ansiedade } \\
\text { caracterizada por realização de } \\
\text { movimentos repetitivos de ida e volta } \\
\text { ao mesmo ambiente e relatos de } \\
\text { insônia. }\end{array}$ & $\begin{array}{l}\text {-Orientar para que não durma nos períodos } \\
\text { da tarde; } \\
\text {-Orientar quanto à realização de atividades } \\
\text { que possam estimular o gasto de energia } \\
\text { como caminhadas, corridas, natação. }\end{array}$ \\
\hline \multirow[t]{2}{*}{$\mathbf{F}$} & \multirow[t]{2}{*}{$\begin{array}{l}\text { Vertigem; } \\
\text { Disfagia; } \\
\text { Dismetria; } \\
\text { Incoordenação motora; } \\
\text { Marcha atáxica }\end{array}$} & $\begin{array}{l}\text { Deambulação prejudicada relacionada } \\
\text { ao prejuizo neuromuscular } \\
\text { caracterizado por capacidade } \\
\text { prejudicada de andar sobre superfícies } \\
\text { regulares necessitando de auxílio. }\end{array}$ & $\begin{array}{l}\text {-Construir mecanismos que facilitem a } \\
\text { deambulação como barras de ferro na casa: } \\
\text {-Disponibilizar apoios como bengalas para o } \\
\text { auxilio da deambulação; } \\
\text {-Auxiliar na redução de barreiras físicas da } \\
\text { casa, como móveis, tapetes. }\end{array}$ \\
\hline & & $\begin{array}{l}\text { Mobilidade física prejudicada } \\
\text { relacionada a prejuízos } \\
\text { neuromusculares caracterizados por } \\
\text { movimentos descoordenados. }\end{array}$ & $\begin{array}{l}\text {-Incentivar a realização de exercícios } \\
\text { passivos e ativos; } \\
\text {-Encaminhar para a fisioterapia. }\end{array}$ \\
\hline \multirow[t]{2}{*}{$\mathbf{E}$} & \multirow[t]{2}{*}{$\begin{array}{l}\text { Disartria; } \\
\text { Dificuldades na deglutição; } \\
\text { Deambulação prejudicada; } \\
\text { Incontinência urinária e } \\
\text { intestinal. }\end{array}$} & $\begin{array}{l}\text { Capacidade de transferência } \\
\text { prejudicada relacionada ao prejuizo } \\
\text { neuromuscular caracterizado por } \\
\text { dificuldade de transferir-se da cama } \\
\text { para a cadeira, cama para posição em } \\
\text { pé. }\end{array}$ & $\begin{array}{l}\text {-Ensinar e orientar os cuidadores sobre a } \\
\text { realização de exercicios passivos e ativos } \\
\text { nos membros superiores e inferiores; } \\
\text {-Encaminhar para o acompanhamento de } \\
\text { um fisioterapeuta. }\end{array}$ \\
\hline & & $\begin{array}{l}\text { Deglutição prejudicada relacionada a } \\
\text { problemas neurológicos caracterizados } \\
\text { por dificuldade para deglutir e } \\
\text { engasgos constantes. }\end{array}$ & $\begin{array}{l}\text {-Orientar o cuidador quanto à observação } \\
\text { da deglutição e o esvaziamento da boca } \\
\text { durante as refeições; } \\
\text {-Monitorar reflexo de tosse durante as } \\
\text { visitas. }\end{array}$ \\
\hline
\end{tabular}

Laboratório de Genética Humana da Unir, 2017.

qualidade de vida e prevenção ou diminuição dos agravos que a doença venha causar futuramente na vida dessas pessoas.

A seguir, serão destacados os problemas identificados durante a anamnese e exame físico, elencando os dois principais diagnósticos de enfermagem, segundo o NANDA: definições e classificação 2015-2017 e intervenções, almejando a melhoria de vida dos indivíduos acometidos pela HD e SCA2 ${ }^{13}$.

Dentre as pessoas afetadas das duas famílias, os indivíduos $\mathrm{A}$ e $\mathrm{E}$ são os mais comprometidos.
Portanto, mais dependentes, necessitando de ajuda para todas as atividades diárias. Os outros indivíduos possuem dificuldades para a realização das atividades de vida diária, mas ainda possuem capacidade funcional para realização de algumas delas, não estando em total dependência no momento atual.

Percebe-se que com o avançar da DNR todos os portadores vão perdendo progressivamente sua autonomia e independência e irão necessitar de cuidados diuturnamente, além de intervenções que amenizem o sofrimento. 


\section{CONCLUSÃO}

Este trabalho permitiu conhecer a estrutura familiar de dois grupos com membros acometidos por DNR. Percebe-se que o vínculo dessas pessoas com os serviços de saúde é frágil, conferindo uma rede de cuidados à saúde falha no reconhecimento das necessidades desta população.

A necessidade de capacitações dos profissionais da atenção primária é perceptível para a realização do acolhimento desses indivíduos, que se encontram perdidos e isolados do sistema de saúde. Além disso, a ausência de orientação quanto ao planejamento familiar pode trazer grande impacto para a família, visto que quase a totalidade dos sujeitos deste estudo está em idade fértil, necessitando de um olhar diferenciado da estratégia de saúde da família.

Em relação à SAE, ressalta-se a necessidade de sua elaboração e implementação por profissionais qualificados, pois assim pode-se garantir a qualidade de vida desses indivíduos, inserindo toda a família na realização do cuidado e dando autonomia nas atividades funcionais de vida diária por maior tempo possível.

Ressalta-se, ainda, a necessidade de implantação de políticas públicas, mediante a situação de vulnerabilidade socioeconômica dessas pessoas, visando o devido acompanhamento e proteção, sobretudo para evitar acidentes e comorbidades.

Conclui-se que tanto o portador de HD quanto o de SCA2 possuem sérios agravamentos durante o percurso da doença, que os levam a comprometimentos irreversíveis, trazendo grande impacto para a família e o doente, que perde sua total autonomia em realizar atividades básicas de vida. Ainda que limitadas, as intervenções realizadas são de fundamental importância para essas pessoas, pois melhoram a autoestima e promovem a qualidade de vida.

\section{REFERÊNCIAS}

1. Coppedè F, Migliore L. DNA damage in neurodegenerative diseases. Mutat Res. 2015; 776:84-7.

2. Kristjanson LJ, Toye C, Dawson S. New dimensions in palliative care: a palliative approach to neurodegenerative diseases and final illness in older people. Med J Aust 2003; 179(6 Suppl): S41.

3. Roos, RAC. Huntington's disease: a clinical review. Orphanet J Rare Dis.2010:5 (40):1-8

4. Kristjanson LJ, Aoun SM, Oldham L. Palliative care and support for people with neurodegenerative diseases and their carrers. Int J Palliat Nurs. 2006: 12(8):368-377.

5. Santos Luz G dos, Silva MRS da, DeMontigny F. Doenças raras: itinerário diagnóstico e terapêutico das famílias de pessoas afetadas. Acta Paul Enferm. 2015; 28(5):395-400.

6. Santos FOF dos, Montezeli JH, Peres AM. Autonomia profissional e sistematização da assistência de enfermagem: percepção de enfermeiros. REME. 2012;16(2): 251-257.

7. Nascimento LC, Dantas IRO, Andrade RD, Mello DF de. Genograma e ecomapa: Contribuições da enfermagem brasileira. Texto \& Contexto Enfermagem.2014; 23(1):211-220.

8. BRASIL. Resolução 466/2012: diretrizes e normas regulamentadoras de pesquisas envolvendo seres humanos. Ministério da Saúde/Conselho Nacional de Saúde; 2012

9. Pereira APS, Teixeira GM, Bressan CAB, Martini JG. O genograma e o ecomapa no cuidado de enfermagem em saúde da família. Rev Bras Enfer. Brasília. 2009; 62(3):407-16.

10. Silva TMR, Alvarenga MRM, Oliveira MAC. Avaliação da vulnerabilidade de famílias assistidas na Atenção Básica. Rev Lat Am Enfermagem. 2012; 20 (5):1-9.

11. Brasil. Conselho Federal de Enfermagem: Resolução n. 358, de 15 de outubro de 2009. Dispõe sobre a SAE e a implementação do processo de enfermagem. Brasília; 2009.

12. Brasil. Lei n. 7.498, de 25 de junho de 1986. Dispõe sobre a regulamentação do exercício da enfermagem e dá outras providências. Diário Oficial da União, Brasilia (DF), 1986; 26 jun. Seção 1:1

13. Diagnósticos de enfermagem da Nanda: definições e classificação 2015-2017. Tradução: Regina Machado Garcez; revisão técnica: Alba Lucia Bottura Leite de Barros et al. Porto Alegre. Artmed; 2015. 